\title{
Transmission Efficiency of 'Candidatus Liberibacter solanacearum' and Potato Zebra Chip Disease Progress in Relation to Pathogen Titer, Vector Numbers, and Feeding Sites
}

\author{
A. Rashed, T. D. Nash, L. Paetzold, F. Workneh, and C. M. Rush
}

Texas A\&M AgriLife Research, 6500 Amarillo Blvd. W., Amarillo, TX 79106.

Accepted for publication 5 July 2012.

\begin{abstract}
Rashed, A., Nash, T. D., Paetzold, L., Workneh, F., and Rush, C. M. 2012. Transmission efficiency of 'Candidatus Liberibacter solanacearum' and potato zebra chip disease progress in relation to pathogen titer, vector numbers, and feeding sites. Phytopathology 102:1079-1085.

With diseases caused by vector-borne plant pathogens, acquisition and inoculation are two primary stages of the transmission, which can determine vector efficiency in spreading the pathogen. The present study was initiated to quantify acquisition and inoculation successes of 'Candidatus Liberibacter solanacearum', the etiological agent of zebra chip disease of potato, by its psyllid vector, Bactericera cockerelli (Hemiptera: Triozidae). Acquisition success was evaluated in relation to feeding site

success was evaluated in relation to vector number (1 and 4$)$ on the plants. Acquisition success was influenced by the feeding site on the plant. The highest acquisition success occurred when insects had access to the whole plant. The results of the inoculation study indicated that the rate of successfully inoculated plants increased with the vector number. Plants inoculated with multiple psyllids had higher bacterial titer at the point of inoculation. Although disease incubation period was significantly shorter in plants inoculated with multiple psyllids, this effect was heterogeneous across experimental blocks, and was independent of pathogen quantity detected in the leaflets 3 days postinoculation. Disease progress was not affected by bacterial quantity injected or psyllid numbers.
\end{abstract} on the host plant as well as the acquisition access period. Inoculation
Additional keywords: inoculation efficiency, potato psyllid.
The existence of tri-trophic interactions among pathogen, vector, and the host underlines the complexity of studying vectorborne plant pathogens and the diseases they cause (10). Due to its direct implications in parameterizing models designed to predict disease dynamics $(3,12,18,24)$, to date, many studies have been conducted to identify variables that affect the transmission process $(1,3,4,23-26)$. Examples of such variables are vector abundance $(3,21)$, competence (12), feeding behavior (13), and the degree of exposure due to the pathogen's heterogeneity of distribution within and among hosts $(5,28)$. Quantifying transmission parameters is particularly needed for emerging diseases where only limited information is available to establish reliable epidemiological models.

Zebra chip (ZC) of potato is an example of a newly emerging plant disease which has been threatening the U.S. potato industry since 2000. The disease was first detected in Texas and subsequently in Nebraska, Colorado, Kansas, New Mexico, Arizona, Nevada, and California (20). Most recently, it has been reported from the major potato-growing regions of Washington, Oregon, and Idaho (7,22). The phloem-limited bacterium 'Candidatus Liberibacter solanacearum' is the etiological agent of $\mathrm{ZC}$ in solanaceous hosts $(8,17)$. ' $C a$. L. solanacearum' is transmitted by a phloem-feeding vector, the potato psyllid Bactericera cockerelli Sulc. (Hemiptera: Triozidae) (20). The aboveground symptoms of ZC-affected potato plants include leaf curling and scorching, shortened internodes, aerial tubers, and, eventually, plant death $(29,31)$. Foliar symptoms, however, may closely resemble those of other insect-mediated potato conditions such as psyllid yellows and purple top $(19,29)$. In potato, $\mathrm{ZC}$ is more readily detectable

Corresponding author: A. Rashed; E-mail address: arashed@ag.tamu.edu

http://dx.doi.org/10.1094/PHYTO-04-12-0094-R

(C) 2012 The American Phytopathological Society by its underground symptoms, because tubers from infected plants show brown discoloration of the vascular ring and darkened medullary ray tissues (20). Tuber symptoms become more pronounced in fried potato tubers (chips or fries) due to changes of amino acid or sugar contents as a consequence of plant physiological response to the infection (30).

Anecdotal observations indicate that $B$. cockerelli preferably feed on leaves that are located in the middle of potato vines $(\mathrm{C}$. Nansen, personal communication). However, B. cockerelli also feeds on host plant petiole and stem tissues (A. R., personal observation). Like many other pathogens, ' $\mathrm{Ca}$. L. solanacearum' is thought to be heterogeneously distributed within the host (31); therefore, feeding on tissues with higher bacterial titer is expected to increase vector exposure to pathogen (26). Indeed, with the Xylella fastidiosa (a leafhopper-transmitted pathogen) system, it was shown that vector feeding location within an infected host may influence acquisition success and, subsequently, transmission efficiency (5).

During sap feeding, ' $\mathrm{Ca}$. L. solanacearum'-positive $B$. cockerelli can inoculate a healthy plant, where the pathogen multiplies and systemically spreads throughout the host (14). Precise knowledge of inoculation mechanism, pathogen transmission efficiency by the vector, and factors that may influence either component not only is important in predicting disease dynamics that follow B. cockerelli arrival early in the season but also, as echoed by Buchman et al. (2), is useful for developing integrated disease management strategies.

The primary objective of this study was to investigate both acquisition and inoculation efficiencies of ' $C a$. L. solanacearum' by its vector, $B$. cockerelli. Acquisition success from different plant sites was evaluated in the form of the proportion of insects that successfully acquired the pathogen and ' $\mathrm{Ca}$. L. solanacearum' quantity acquired. Our evaluation of inoculation success was set to (i) determine whether B. cockerelli titer (bacterial quantity) 
load is a predictor of a successful inoculation event and evaluate whether the quantity of the inoculated ' $\mathrm{Ca}$. L. solanacearum' titer (or inoculation level) correlates with ' $\mathrm{Ca}$. L. solanacearum' titer within $B$. cockerelli, (ii) evaluate the effect of vector number and titer load of the bacteriliferous psyllids on ' $\mathrm{Ca}$. L. solanacearum' transmission success (while controlling for feeding site), and (iii) quantify the effect of vector number and titer load on $\mathrm{ZC}$ incubation period (i.e., time from initial infestation or infection to symptom appearance) and the rate of ZC development.

\section{MATERIALS AND METHODS}

Insect colonies. Two colonies of ' $\mathrm{Ca}$. L. solanacearum'negative potato psyllids, each in a 60 -by-60-by-60-cm mesh-andclear plastic cage bugdorm 2 (BioQuip, Rancho Dominquez, CA), were established 3 months prior to the acquisition study. In each colony, the absence of ' $\mathrm{Ca}$. L. solanacearum' was confirmed at different time intervals by quantitative polymerase chain reaction (qPCR) analyses of 10 to 20 randomly selected psyllids. This screening was done initially upon psyllid arrival and then was repeated two times after colony establishment on week 8 and week 10, just before the acquisition experiment. Each of the two 'Ca. L. solanacearum'-negative colonies contained four potato plants (Solanum tuberosum 'FL1867') as hosts. Petiole samples (1/plant) of host plants tested negative for ' $\mathrm{Ca}$. L. solanacearum'.

For the inoculation study, experimental insects were obtained from a ' $\mathrm{Ca}$. L. solanacearum'-infected greenhouse population of B. cockerelli, which was maintained at the Texas AgriLife Research greenhouse facility at Bushland, TX for several generations. To initiate the colonies, bacteriliferous psyllids were kindly provided by J. Munyaneza at the United States Department of Agriculture (USDA) Agricultural Research Service, Wapato, WA. These potato psyllids were originally collected from central and northern Texas. Insects were reared on four to five potato plants (FL1867) in two 60-by-60-by-60-cm mesh-and-clear plastic bugdorm cages. The dead plants in each bacteriliferous colony were replaced by healthy plants as needed (approximately every 5 to 6 weeks). The greenhouse temperature was set to fluctuate between 20 and $26^{\circ} \mathrm{C}$.

Acquisition study. Experiments were conducted under greenhouse condition in January 2012. There were five experimental replicates. Each replicate consisted of a single ' $\mathrm{Ca}$. L. solanacearum'-infected potato plant. To prepare infected experimental plants, seed potato tubers (FL1867) were planted in 1-gallon pots of 2:1 potting soil/sand mix. Two weeks after emergence, each plant was infested with 10 bacteriliferous psyllids for 10 days. Plants were kept in the greenhouse and, 9 weeks after infestation, 'Ca. L. solanacearum'-negative adult psyllids were placed on the infected plants and restricted to feed on leaflet $(n=10$ to 12 psyllids/plant), petiole ( $n=10$ to 12 ), and stem ( $n=10$ to 12 ) tissues of the same infected plant, using 1-in. frame-less clip cages (BioQuip). Each clip cage contained 5 to 6 B. cockerelli. The whole plant was then placed in a 60-by-60-by-60-cm meshand-clear plastic cage. A cardboard surface was placed on top of the 1-gallon pots so that only plant tissue was exposed to the insects. Next, 16 to 20 ' $C a$. L. solanacearum'-negative $B$. cockerelli were released into the cage. This approach allowed this last group of insects to have access to the whole plant. Six psyllids per plant site treatment and half of the whole-plant treatment psyllids were collected in $24 \mathrm{~h}$. The remaining psyllids were collected after $48 \mathrm{~h}$. This allowed us to evaluate the effect of acquisition access period (AAP) on acquisition success and the ' $\mathrm{Ca}$. L. solanacearum' quantity acquired (acquisition level) by B. cockerelli. Insects were placed in a $-20^{\circ} \mathrm{C}$ freezer immediately after the AAP elapsed and were extracted individually the following day. After insect removal, the respective plant tissues (petioles, leaflets, and stems) were analyzed for bacterial titer using relative qPCR.
Inoculation study. Experiments were conducted in three time blocks each in a large greenhouse cube cage (6-by-6-by-6-ft; BioQuip) during fall 2011 (blocks 1 and 2) and winter 2012 (block 3 ). Adult psyllids were caged on a single leaflet/plant $\approx 2$ weeks after plant emergence. Experimental seed potato samples of a yellow table cultivar were kindly provided by the CSS Farms (Bakersfield, CA). Then, 1-in. frame-less clip cages (BioQuip) were placed at the tip of a terminal leaflet of a compound leaf located in the middle of the main shoot, such that insects had access to both surfaces of the leaflet. Each block included two treatments. In block one (September 2011), 23 plants were inoculated with a single psyllid and another 23 plants were inoculated with four psyllids per clip cage. There were two no-psyllid control plants per treatment per block. All ' $\mathrm{Ca}$. L. solanacearum'positive psyllids used in this study originated from the same colony. The second (October 2011) and third (January 2012) blocks included additional plants infested with one and four ' $\mathrm{Ca}$. L. solanacearum'-negative psyllids to control for psyllid presence. ' $C a$. L. solanacearum'-positive $B$. cockerelli were allowed to feed on healthy potato plants for a $24-\mathrm{h}$ inoculation access period (IAP). Cages were inspected three times during IAP to assure insect "feeding"; immobile positioning of psyllids on the leaflet was considered feeding. After the IAP elapsed, insects were removed and stored at $-80^{\circ} \mathrm{C}$ for later qPCR analysis. Plants were immediately sprayed with insecticide (M-Pede; Mycogen Co., San Diego, $\mathrm{CA}$ ) to eliminate escapees (only two escaped in the second block). Mean greenhouse temperatures during the fall and winter experimental periods were $22.8 \pm 1.6$ and $24.9 \pm 2.4^{\circ} \mathrm{C}$, respectively. Insecticide was reapplied on days 4 and 8 postinoculation to eliminate any eggs that might have hatched. The likelihood of an egg-hatching event was nearly zero because leaflet areas covered by the clip cages were removed 3 days post-inoculation for molecular analysis to assess inoculation success and inoculation level. A 3-day delay was applied to assure bacterial movement from the point of inoculation into the rest of the leaflet or leaf for evaluation of disease progress. Plants were watered and fertilized as needed. Bacterial populations in individual psyllids (psyllid titer load) and leaflets (plant titer load) were quantified using qPCR. ZC symptom severity on infected plants was recorded every 2 days based on a 0 to 4 scale (with 0 being healthy and 4 being a dead plant). A score of 1 was given to a plant that started to develop aerial tubers and showed upward rolling of its fresh leaves. At score 2, the plant had many rolled leaves, multiple aerial tubers, and also started to show some leaf scorch; the diseased plant was readily detectable at this stage. Plants with the score 3 had a lot of scorched leaves but still had some green leaf tissue. The term "incubation period" reflects the number of days it took for visual symptoms to appear. The ratio of successful inoculation (inoculation success) was measured as the proportion of plants whose inoculated leaflets tested positive for ' $C a$. L. solanacearum' (using qPCR) to the total number of plants in that treatment.

DNA extraction. A slightly modified version of the commercial DNeasy Blood and Tissue Kit (Qiagen) protocol was used to extract total DNA from experimental insects; the psyllids, from the acquisition and inoculation experiments, were individually placed into screw cap tubes along with a $2.5-\mathrm{mm}$ stainless-steel ball bearing bead. Tubes were then placed in liquid nitrogen for $\approx 2$ min and ground using a Hard Tissue Grinder (VWR, Sugar Land, TX). Thereafter, the standard protocol was followed by adding $20 \mu \mathrm{l}$ of proteinase K and $200 \mu \mathrm{l}$ of AL buffer. Sample DNA was eluted with $50 \mu \mathrm{l}$ of the elusion buffer.

Leaf tissue was ground in a homogenizer following a 2-min placement in liquid nitrogen. Plant extractions were performed following DNeasy Plant Mini Kit (Qiagen) protocol. Final plant DNA product was eluted in $100 \mu$ of the elusion buffer.

DNA quantification. Comparative cycle threshold $(\mathrm{Ct})$ method, also known as $\Delta \Delta \mathrm{Ct}$, was performed with an Applied Biosystems 7500 Real-Time PCR System (ABI). The reaction mix contained 
TaqMan Universal Master Mix (Applied Biosystems), $0.05 \mu \mathrm{M}$ forward primer $\mathrm{LsoF}(15)$ for insects $(0.3 \mu \mathrm{M}$ for plants), $0.05 \mu \mathrm{M}$ reverse primer $\operatorname{HLBr}(16)$ for insects $(0.3 \mu \mathrm{M}$ for plants), and 0.25 $\mu \mathrm{M}$ HLBp TaqMan probe for both insects and plants (16). Eukaryotic 18S rRNA (VIC/MGB probe, primer limited; Applied Biosystems) was used as the endogenous control for both insects and plants. The amount of target in each plant sample was normalized to the ' $C a$. L. solanacearum' endogenous reference and quantified in relation to the calibrator (known to contain 6,250 genomes in inoculation and acquisition experiments). The amount of target in insect samples was quantified in relation to calibrators $\left(5 \times 10^{6}\right.$ genomes in inoculation and 1,562.5 genomes in acquisition experiments). ABI default analysis software was used; multiple plates were analyzed using the plate study doc. function.

Statistical analyses. Acquisition success analyses. A binary logistic regression model was used to examine whether the probability of a successful acquisition can be predicted by feeding site. Plant replicate, AAP, and feeding location were treated as categorical co-variables. Analysis of variance (ANOVA) was used to evaluate whether acquired ' $C a$. L. solanacearum' quantities by insects was affected by plant replicate, AAP, or feeding site. Logtransformed psyllid titer loads (bacterial quantity) were normally distributed within plant site treatments (Kolmogorov-Smirnov, $P>0.07$ ), with the exception of leaflet treatment (KolmogorovSmirnov $=0.219, P=0.003$ ). Factors with nonsignificant effect (if $P>0.1$ ) were removed from the final model (i.e., plant replicate and AAP) in a stepwise approach.

Inoculation success analyses. A binary logistic regression model, with block and treatment (single or multiple psyllid) as categorical co-variables and vector titer load as the continuous covariable, was used to compare the inoculation success. Insect titer load in multiple-psyllid treatments was the average bacterial quantities detected in each of the four insects. ANOVA was used to compare plant bacterial quantities (measured as PCR-produced RQ values), ZC disease progress, and disease incubation period of plants inoculated with either single- or multiple-psyllid treatments. In the entire generalized linear models, block, treatment, and the interaction between the two were included as factors. To maximize statistical power, block and the interaction terms were removed in a stepwise manner if they had no effect. Logtransformed bacterial quantities at the point of inoculation were normally distributed in blocks 2 and 3 (Shapiro-Wilk, $P>0.450$ ) but slightly deviated in block one (Shapiro-Wilk, $P=0.011$ ). Square-root-transformed disease incubation periods were normally distributed in the single-psyllid treatment (Shapiro-Wilk, $P=0.054$ ) but not in the multiple-psyllid treatment (Shapiro-Wilk, $P<0.001)$. ZC disease progress rate was compared between the single- and multiple-psyllid treatments 2 months postinoculation.

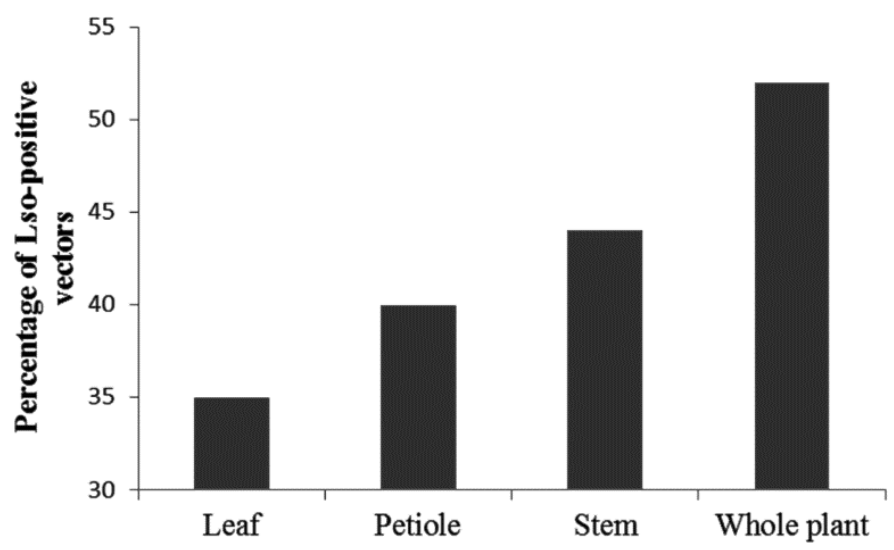

Fig. 1. Overall percentage of vectors that acquired 'Candidatus Liberibacter solanacearum' from different potato plant tissues across five replicates.
Per-day disease progress was calculated by subtracting the first observed disease score $(0.5$ in all cases) from the disease score recorded 60 days postinoculation and dividing this number by the number of the days since disease appearance. All statistical analyses were performed in IBM SPSS Statistics (version 19; IBM SPSS, Armonk, NY).

\section{RESULTS}

Acquisition success from different plant tissue by $B$. cockerelli. Probability of a successful acquisition event was not affected by plant replicate (Wald $\chi^{2}{ }_{4}=5.81 ; P=0.214$ ) or AAP $\left(24\right.$ versus $48 \mathrm{~h}$ ) on infected plant tissue (Wald $\chi_{2}^{2}=0.006 ; P=$ $0.936)$. Feeding location on the plant, however, was a significant predictor of a successful acquisition event (Wald $\chi^{2}{ }_{3}=12.27 ; P=$ 0.007) (Fig. 1). Insects which were exposed to the whole plant $(52.8 \%)$ and the ones with access to the stem tissue (44.4\%) had the highest ' $C a$. L. solanacearum' acquisition success ratios.

' $C a$. L. solanacearum' titer did not differ among stem, petiole, and leaflet tissues $\left(F_{8,11}=0.605 ; P=0.757\right)$. On average $( \pm$ standard error [SE]), relative quantifications were estimated to be 81.9 (25.24) for leaflet, 77.15 (23.63) for stem, and 74.76 (15.07) for petiole tissues ( $n=5$ plants).

' $C a$. L. solanacearum' titer load acquired by B. cockerelli from different plant tissue. Pathogen quantity acquired by $B$. cockerelli was not affected by the AAP $\left(F_{1,109}=2.01 ; P=0.160\right)$ and this factor was removed from the model in a stepwise approach. Likewise, the amount of pathogen acquired by $B$. cockerelli was not influenced by the plant site where feeding occurred $\left(F_{3,110}=1.23 ; P=0.302\right)$. However, insects showed a tendency to acquire higher pathogen quantities when they were given access to the whole plant, or to the stem tissue, compared with when they were restricted to feed on petioles and leaflets (Fig. 2). No significant effect of plant replicate was detected $\left(F_{4,110}=2.09 ; P=0.08\right)$.

Inoculation success by the $B$. cockerelli vector. Plants with multiple psyllid vectors were inoculated at a significantly higher rate compared with the plants with a single psyllid (Wald $\chi_{1}^{2}=$ 20.29; $P<0.001$ ) (Fig. 3). Overall, across blocks, molecular detection was indicative of an $85.2 \%$ inoculation success ratio (measured as the proportion of successful inoculation events to the total number of plants) in the multiple-psyllid treatment compared with a $46.03 \%$ success in the single-psyllid treatment. A significant block effect was detected (Wald $\chi_{2}^{2}=13.96 ; P=$ 0.001 ) and, thus, block remained as a categorical variable in the final model (Fig. 4). The probability of a successful inoculation was not affected by the vector titer load (Wald $\chi^{2}{ }_{1}=0.077 ; P=$ $0.781)$.

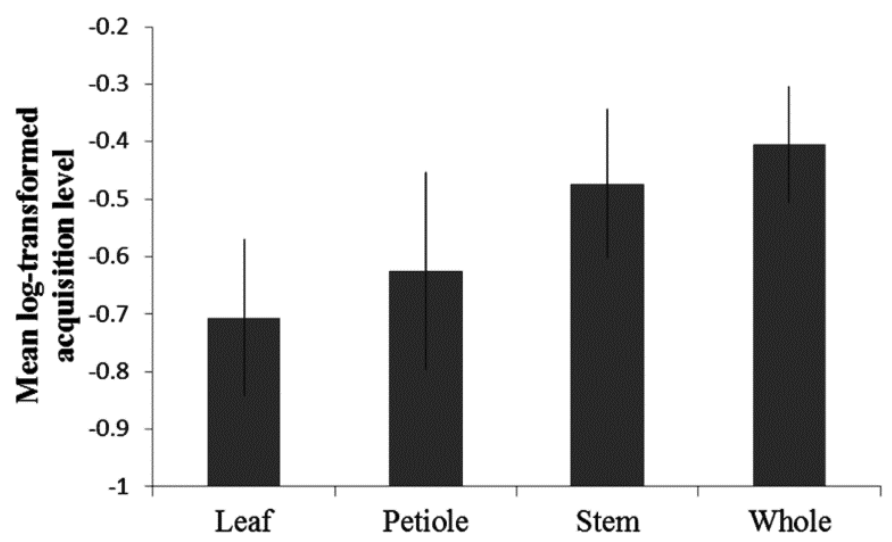

Fig. 2. Pathogen quantity acquired by individual Bactericera cockerelli (acquisition level) while feeding on different tissues of potato plants infected with 'Candidatus Liberibacter solanacearum'. Error bars represent \pm standard error. 
' $\mathrm{Ca}$. L. solanacearum' quantity at the point of inoculation. Compared with the plants inoculated with a single psyllid, plants inoculated with four psyllids had a significantly higher bacterial quantity at the point of inoculation $\left(F_{1,77}=7.52 ; P=0.008\right)$ (Fig. $5)$. Although plant titer loads at the point of inoculation were not statistically affected by psyllid titer, the relationship was of borderline significance $\left(F_{1,77}=3.73 ; P=0.057\right)$. We failed to detect and quantify bacteria in three of the plants which eventually developed ZC disease.

ZC incubation period. Although symptoms, on average, appeared 4 days earlier in plants that were inoculated with multiple psyllids (mean \pm SE: $42.4 \pm 0.52$ ) than plants inoculated with a single psyllid (mean \pm SE: $46.5 \pm 2.02)\left(F_{2,42}=14.2 ; P<0.001\right)$, there was also a significant block-treatment interaction $\left(F_{1,42}=\right.$ 22.9; $P<0.001$ ) (Fig. 6A to C). A significant block effect also was observed $\left(F_{1,42}=17.9 ; P<0.001\right)$. In all of the cases, disease symptoms initially appeared as curly, newly emerged leaves and small aerial tubers at the budding points. Disease incubation period was not affected by the initial pathogen titer detected in leaflets following inoculation $\left(F_{1,42}=0.05 ; P=0.816\right)$. Overall, 40 of 81 ' $C a$. L. solanacearum'-positive plants (confirmed by qPCR at the point of inoculation) never developed disease symptoms.

ZC disease progress rate. Neither the number of psyllids per plant $\left(F_{1,33}=0.32 ; P=0.574\right)$ nor bacterial quantity at the point of inoculation $\left(F_{1,33}=0.007 ; P=0.932\right)$ predicted disease progress rate of the infected potato hosts. The average per-day disease progress rates were $0.098( \pm 0.015)$ and $0.11( \pm 0.008)$ for single- and multiple-psyllid treatments, respectively. Two months postinoculation in our four-psyllid treatment, 53.3, 84.6, and $100 \%$ of the infected plants were expressing symptom scores of at least 2 (based on a 0 to 4 scale) in blocks 1,2 , and 3, respectively. In the single-psyllid treatment, 16.6, 77.7, and $100 \%$ of the infected plants expressed a symptom score of $\geq 2$ in blocks 1,2 , and 3, respectively. The increase in the speed of disease progress through the season was spotted by the observed significant block effect $\left(F_{2,44}=14.08 ; P<0.001\right)$. However, treatments behaved similarly within blocks, as revealed by the nonsignificant treatment-block interaction $\left(F_{2,42}=1.36 ; P=0.268\right)$. At score 2, diseased plants could be readily identified. As mentioned earlier,

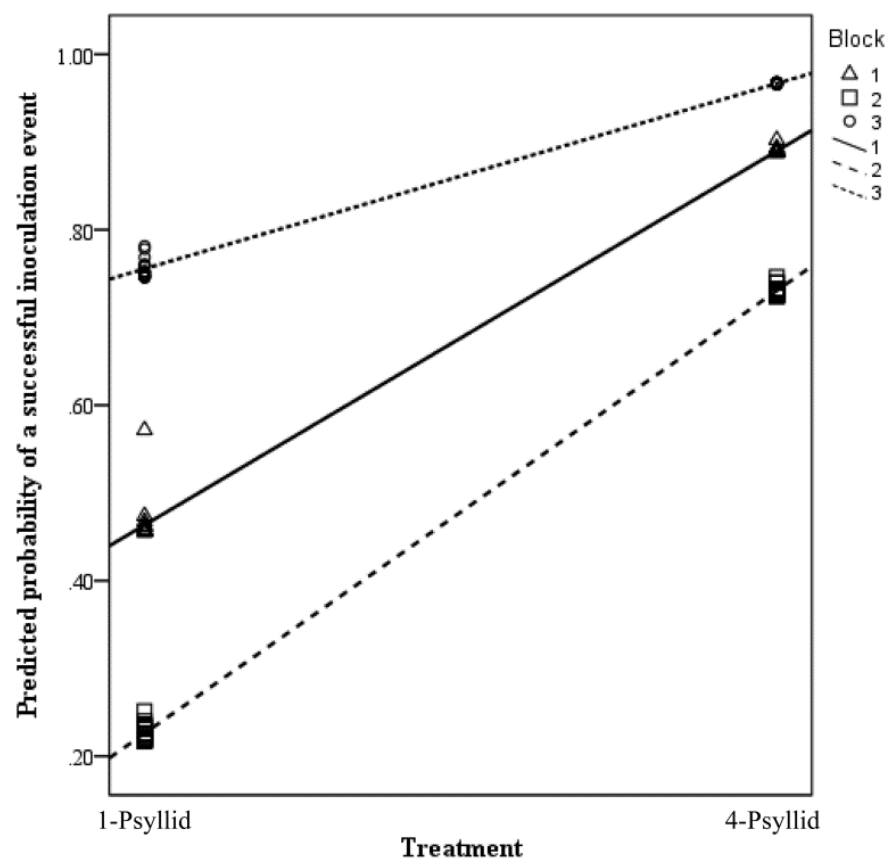

Fig. 3. Predicted probability of an inoculation event of 'Candidatus Liberibacter solanacearum' by Bactericera cockerelli in one-psyllid and fourpsyllid treatments in blocks 1,2 , and 3 . curling of newly emerged leaves and swollen leaf buds were attributed to early stages of ZC disease. As the disease progressed, aerial tubers grew in size and increased in number. New plant growth was associated with shortened internodes and smaller and yellowish leaves. Late stages of the disease (scores 3 to 4) were specified by stems with very few fully expanded leaves and severe leaf-scorch and multiple relatively large aerial tubers (1.5 to $2 \mathrm{~cm}$ in diameter).

\section{DISCUSSION}

In this greenhouse study, acquisition and inoculation efficiencies were assessed as both the proportion of successful acquisition or inoculation events and the bacterial quantities acquired from and injected into the potato host by the vector. In the potato host, the amount of pathogen acquired by $B$. cockerelli was not influenced by the feeding site. However, the proportion of psyllids that successfully acquired the pathogen was higher on the stem tissue compared with leaflets and petioles. The highest percentage of acquisition success occurred when insects had access to the whole plant. Higher proportions of inoculation events and bacterial titer in the inoculated leaflets were obtained with multiple psyllids per plant compared with single-psyllid inoculation. However, titer load within the insects was not a predictor of inoculation success. ZC disease progress rate appeared to be independent of both the amount of initial titer load and the number of the $B$. cockerelli on the plant. Although disease incubation period was overall affected by the number of bacteriliferous psyllids, results were not consistent across all three time blocks.

The effect of feeding site on acquisition success and, subsequently, transmission efficiency has been shown in other vector-

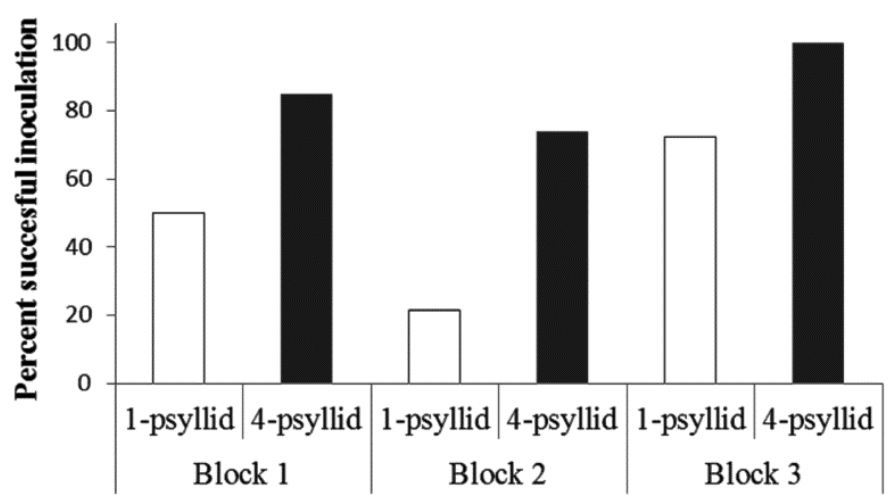

Fig. 4. Percentage of successful inoculation events of 'Candidatus Liberibacter solanacearum' by Bactericera cockerelli in one-psyllid and four-psyllid treatments in each experimental block.

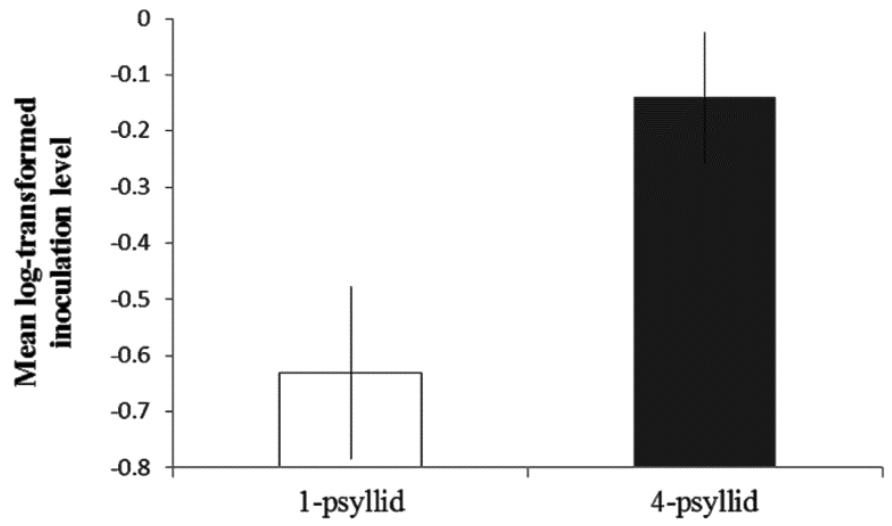

Fig. 5. Quantity of 'Candidatus Liberibacter solanacearum' at the point of inoculation (inoculation level) in one-psyllid and four-psyllid treatments. Error bars represent \pm standard error. 
borne pathogen systems, where the pathogen was heterogeneously distributed within the host $(1,5)$. Likewise, in the present study, the proportion of insects that successfully acquired the pathogen was significantly different on various plant sites but was not affected by AAP. However, here, the proportion of insects that acquired ' $C a$. L. solanacearum' was not dependent upon bacterial quantity in the tissue where feeding occurred. Although ' $\mathrm{Ca}$. L. solanacearum' is more readily detectable in stem compared with leaf and petiole tissue of the infected potato host (31), our analysis of bacterial titer in stem, petiole, and leaflet tissues revealed no difference in bacterial quantities. This observed homogeneity, as well as the distribution pattern of the pathogen (e.g., leaflets with slightly higher pathogen quantities), may be attributed to the fact that the experiments were conducted under controlled greenhouse conditions. Moreover, plants were originally infested with 10 potato psyllids, which were free to move and feed on different tissues. Given the observed difference in acquisition probability of insects on different plant sites, despite of the lack of variation in bacterial titer among stem, petiole, and leaflets, it is possible that insect feeding behavior on these sites determines its ability to acquire the pathogen. The observed higher acquisition success of insects with access to the whole plant may also be due to stress or limited mobility of the caged insects. Although this may be a possibility, differences still existed among insects which were caged on different plant sites (Fig. 1). A larger number of insects per plant site may reveal a stronger relationship between AAP and acquisition success, which can be the subject of future studies. Our failure to detect any significant effect of AAP (24 versus $48 \mathrm{~h}$ ) is supported by Almeida and Purcell (1). In their study with Homalodisca vitripennis Garmer (Hemiptera: Cicaldellidae) vector, the acquisition efficiency of the bacterium $X$. fastidiosa is not affected by AAP beyond $6 \mathrm{~h}$ of access. Our results indicate that transmission efficiency may be affected by psyllid feeding site, because at least the probability of acquisition is determined by this factor. Whether vector ability in inoculating ' $\mathrm{Ca}$. L. solanacearum' into the host is also affected by the feeding site should be the subject of future studies.

The observed difference in inoculation success between singlepsyllid and multiple-psyllid treatments is in agreement with the work done by Buchman et al. (2), who reported a transmission rate of $100 \%$ (5 of 5) for a 20-psyllid treatment and 21\% (4 of 19) for a single-psyllid treatment, following a 24-h IAP. In the present study, however, the overall inoculation success of the four-psyllid treatment was $85 \%$, compared with $46 \%$ for the single-psyllid treatment. Our work complements that of Buchman and colleagues in several ways. Here, the experimental insects were caged on a single leaflet and potential variations due to feeding site effect were eliminated by this approach $(5,6)$. This allowed for a more controlled objective measure and a direct comparison of inoculation efficiencies between treatments. Furthermore, in this study, titer loads within the plant were quantified at the points of inoculation where feeding occurred. This allowed us, first, to conclude the absence of a relationship between plant initial titer load and the rate of disease progress; and, second, to show that inoculation efficiency (both inoculation ratio and level) is independent of the titer load within B. cockerelli. The lack of correlation between pathogen quantity within the vector and inoculation success indicates that differences in transmission efficiency of single- and multiple-psyllid treatments may be influenced by the number of probing or feeding events.

A similar lack of correlation between pathogen titer within the vector and inoculation efficiency was reported with Pierce's disease and the xylem-limited bacterium $X$. fastidiosa. Hill and Purcell (9) showed that, in a grapevine host, the transmission efficiency of the pathogen by its leafhopper vector (Graphocephala atropunctata Signoret [Hemiptera: Cicadellidae]) was not associated with the pathogen titer in the insect. Likewise, Jackson and colleagues (11) concluded that, in a Chrysanthemum host,
$X$. fastidiosa inoculation level was not affected by the pathogen quantity within the vector, $H$. vitripennis. Although supported by previous studies, our failure to detect such a correlation could also be attributed to the 3-day sampling delay. During this time, ' $C a$. L. solanacearum' might have continued to multiply and, therefore, masked the initial variation in the injected bacterial quantities. This delay, however, was essential to assure bacterial translocation away from the point of inoculation for later disease progress assessment. Indeed, 40 of 81 successfully inoculated plants never developed ZC during the 10-week observation period, which suggests that that the inoculum may have been removed by sampling the leaflet prior to its systemic translocation (14).

Although the overall incubation period was significantly longer in the single-psyllid treatment, a significant block-treatment interaction was detected by the model. This significant interaction was, in part, due to one single outlier in the one-psyllid treatment of block 2 (Fig. 6B), where symptoms appeared only 33 days
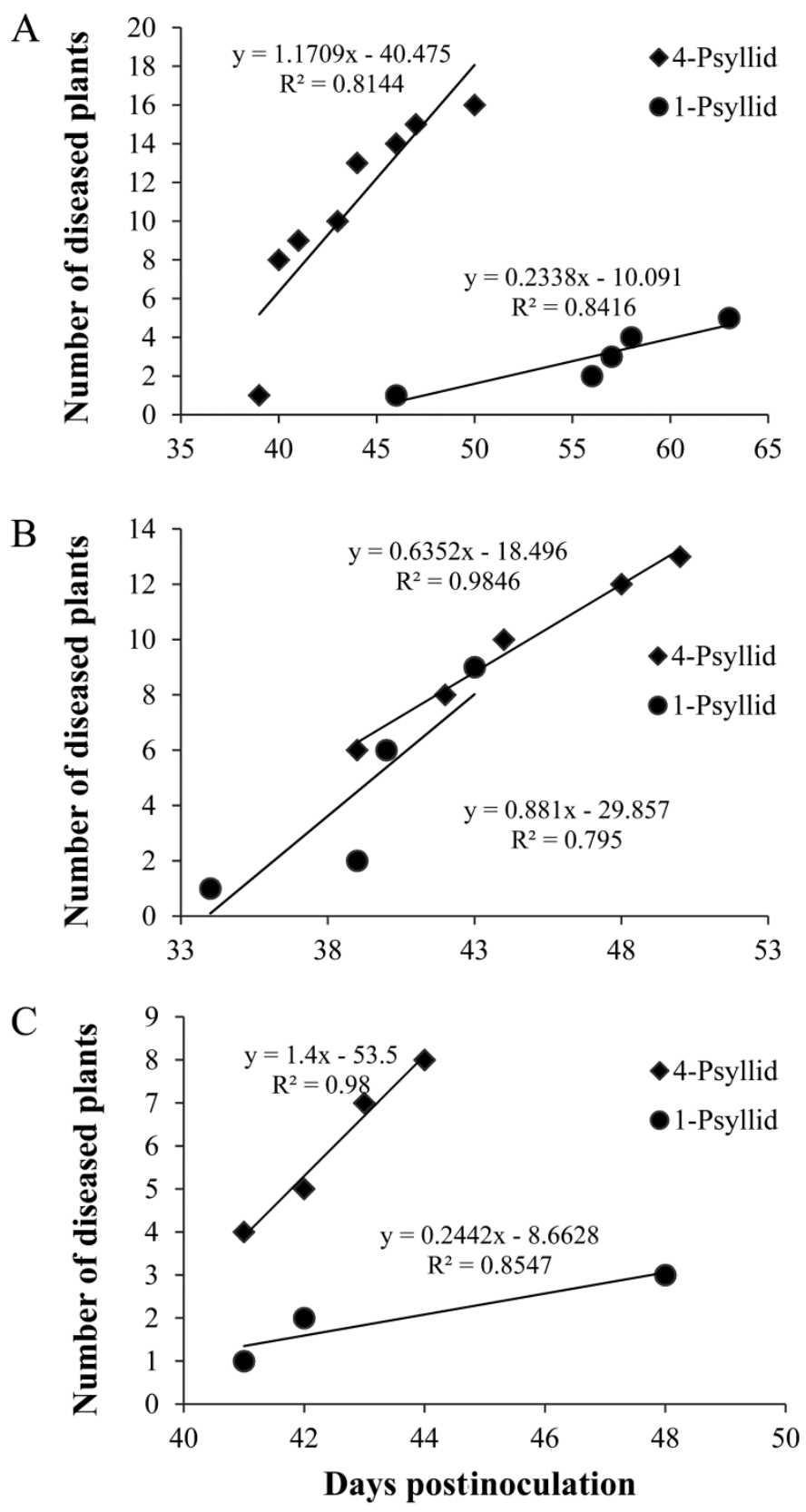

Fig. 6. Representation of cumulative increase in the number of symptomatic plants in relation to the number of days postinoculation in blocks $\mathbf{A}, 1 ; \mathbf{B}, 2$; and $\mathbf{C}, 3$. 
after inoculation, 6 days before symptom appearance in the next plant. The overall treatment effect resulted from the strong significant between-treatment difference in the first time block (Fig. 4). Although the observed incubation periods in our experiments were supported by the greenhouse study of Levy and colleagues (14), where they also reported 5 to 6 weeks of $\mathrm{ZC}$ incubation period in less-susceptible cultivars, ZC incubation period was considerably shorter ( 22 to 25 days) in the field (27). In the field study, however, 30 psyllids had access to the whole plant for 1 week of IAP. Thus, the number of bacteriliferous psyllids, the plant site where feeding occurs, and IAP may be some of the contributing factors that determine the speed of disease appearance in the infected hosts.

Once symptoms appeared, the rate of disease progress was independent of both the vector number and the initial plant titer load. This indicates that vector number may affect the time it takes for disease expression, due to difference in initial injected inoculum load; however, following bacterial multiplication and systemic movement within the host (14), disease progresses at the same rate between treatments. Disease progress rates consistently increased throughout the experimental blocks. For instance, whereas $100 \%$ of the infected plants in both treatments of block 3 showed a symptom score of at least 2, only 81.1 and $35 \%$ of infected plants (average of both treatments) in blocks 2 and 1, respectively, reached this level of symptom severity. Higher greenhouse temperatures during winter or plant physiological changes (i.e., plant response to reduced daylight) may have influenced host susceptibility to ' $\mathrm{Ca}$. L. solanacearum' infection. The later explanation may be more probable because, based on field experiments, temperature variation did not affect disease progress rate (27).

Although field experiments provide valuable information which directly assists in planning regional management approaches, the present greenhouse study was designed to minimize environmental complexity and variability. This allowed for a precise evaluation of factors that potentially influence pathogen-plantvector interactions. Quantification of variables that can affect the transmission process and spatio-temporal disease development is essential for developing models to design and evaluate integrated vector-borne disease management strategies (12). The probability of ' $C a$. L. solanacearum' acquisition by $B$. cockerelli was influenced by the feeding site on the potato host. Vector number was a factor that determined inoculation success of ' $\mathrm{Ca}$. L. solanacearum' into the potato host. However, inoculation success rate was independent of pathogen quantity within B. cockerelli. Although incubation period for the plants inoculated with multiple insects was significantly shorter than for plants inoculated with one insect, this finding needs to be interpreted with caution due to the observed heterogeneity of response between our three blocks. Verification of this effect should be a pursuit of future research.

Results of this study support the current perception that insecticide application regiments aimed at knocking down vector populations need to be continued. The observed high inoculation success rate of $B$. cockerilli in a relatively short IAP indicates that chemicals need to be applied based on a precisely calculated schedule and, ideally, should have an immediate effect on the insect. The latter needs particular attention because (i) $B$. cockerelli, especially during nymphal stages, tend to feed on the adaxial leaf surface where adequate coverage with contact based pesticides is difficult to achieve and (ii) for systemic pesticides to work effectively, they need to be ingested by the vector through feeding; hence, they may not be effective in stopping initial infections given the observed, relatively short IAP. Studies on genetic or morphological factors, which could negatively impact vector feeding rate and also restrict pathogen multiplication or movement, are needed to develop resistant cultivars as part of an integrated pest management program.

\section{ACKNOWLEDGMENTS}

Funding for this research was provided by USDA-Specialty Crop Research Initiative Zebra Chip award number 2009-51181-20176 and by the Texas Department of Agriculture, Zebra Chip Research Initiative. We thank M. Smith, J. Arthur, and B. Bryan and undergraduate assistants S. Pattison, C. Archer, and B. Bealmear for their help during the course of this study; and J. Price for helpful discussions.

\section{LITERATURE CITED}

1. Almeida, R. P. P., and Purcell, A. H. 2003. Transmission of Xylella fastidiosa to grapevines by Homalodisca coagulata (Hemiptera: Cicadellidae). J. Econ. Entomol. 96:264-271.

2. Buchman, J. L., Sengoda, V. G., and Munyaneza, J. E. 2011. Vector transmission efficiency of Liberibacter by Bactericera cockerelli (Hemiptera: Triozidae) in zebra chip potato disease: effects of psyllid life stage and inoculation access period. J. Econ. Entomol. 104:1486-1495.

3. Daugherty, M. P., and Almeida, R. P. P. 2009. Estimating Xylella fastidiosa transmission parameters: decoupling sharpshooter number and feeding period. Entomol. Exp. Appl. 132:84-92.

4. Daugherty, M. P., Bosco, D., and Almeida, R. P. P. 2009. Temperature mediates vector transmission efficiency: Inoculum supply and plant infection dynamics. Ann. Appl. Biol. 155:361-369.

5. Daugherty, M. P., Lopes, J. R. S., and Almeida, R. P. P. 2010. Vector within-host preference mediates transmission of a heterogeneously distributed pathogen. Ecol. Entomol. 35:360-366.

6. Dekker, T., Takken, W., Knols, B. G. J., Bouman, E., van de Laak, S., Bever, A., and Huisman, P. W. 1998. Selection of biting sites on a human host by Anopheles gambiae s.s., An. arabiensis and An. quadriannlatus. Entomol. Exp. Appl. 87:295-300.

7. Hamm, P. B., Rondon, S. I., Crosslin, J. M., and Munyaneza, J.E. 2011. A new threat in the Columbia Basin of Oregon and Washington: zebra chip. Pages 1-5 in: Proc. 11th Annu. SCRI Zebra Chip Rep. Session. F. Workneh, A. Rashed, C. M. Rush, eds. Frederic Printing, Aurora, CO.

8. Hansen, A. K., Trumble, J. T., Stouthamer, R., and Paine, T. D. 2008. A new huanglongbing species, 'Candidatus Liberibacter psyllaurous,' found to infect tomato and potato, is vectored by psyllid Bactericera cockerelli (Sulc). Appl. Environ. Microbiol. 74:5862-5865.

9. Hill, B. L., and Purcell, A. H. 1995. Multiplication and movement of Xylella fastidiosa within grapevine and four other plants. Phytopathology 85:1368-1372.

10. Irwin, M. E., and Thresh, J. M. 1990. Epidemiology of Barley yellow dwarf: a study in ecological complexity. Annu. Rev. Phytopathol. 28:393424.

11. Jackson, B. C., Blua, M. J., and Bextine, B. 2008. Impact of duration versus frequency of probing by Homalodisca vitripennis (Hemiptera: Cicadellidae) on inoculation of Xylella fastidiosa. J. Econ. Entomol. 101:1122-1126.

12. Jeger, M. J., Holt, J., Van den Bosch, F., and Madden, L .V. 2004. Epidemiology of insect-transmitted plant viruses: Modeling disease dynamics and control interventions. Physiol. Entomol. 29:291-304.

13. Kilpatrick, A. M., Kramer, L. D., Jones, M.J., Marra, P. P., and Daszak, P. 2006. West Nile virus epidemics in North America are driven by shifts in mosquito feeding behavior. PLoS Biol. 4:606-610.

14. Levy, J., A. Ravindran, Gross, D., Tamborindeguy, C., and Pierson, E. 2011. Translocation of 'Candidatus Liberibacter solanacearum', the zebra chip pathogen, in potato and tomato. Phytopathology 101:1285-1291.

15. Li, W., Abad, J. A., French-Monar, R. D., Rascoe, J., Wen, A., Gudmestad, N. C., Secor, G. A., Lee, I., Duan, Y., and Levy, L. 2009. Multiplex real-time PCR detection for identification and quantification of 'Candidatus Liberibacter solanacearum' in potato plants with zebra chip. J. Microbiol. Methods 78:59-65.

16. Li, W., Hartung, J. S., and Levy, L. 2006. Quantitative real-time PCR for detection and identification of Candidatus Liberibacter species associated with citrus huanglongbin. J. Microbiol. Methods 66:104-115.

17. Liefting, L. W., Perez-Egusquiza, Z. C., Clover, G. R. G., and Anderson, J. A. D. 2008. A new 'Candidatus Liberibacter' species in Solanum tuberosum in New Zealand. Plant Dis. 92:1474.

18. Madden, L. V., Jeger, M. J., and Van den Bosch, F. 2000. A Theoretical assessment of the effects of vector-virus transmission mechanism on plant virus disease epidemics. Phytopathology 90:576-594.

19. Munyaneza, J. E., Crosslin, J. M., and Buchman, J. L. 2009. Seasonal occurrence and abundance of the potato psyllid, Bactericera cockerelli, in south central Washington. Am. J. Pot. Res. 86:513-518.

20. Munyaneza, J. E., Crosslin J. M., and Upton, J. E. 2007. Association of Bactericera cockerelli (Homoptera: Psyllidae) with "Zebra Chip," a New Potato Disease in Southwestern United States and Mexico. J. Econ. Entomol. 100:656-663. 
21. Ng, J. C., and Perry, K. L. 2004. Transmission of plant viruses by aphid vectors. Mol. Plant Pathol. 5:505-511.

22. Nolte, P., Olsen, N., Wenninger, E., and Thornton, M. 2011. Zebra chip found in Idaho. Page 6 in: Proc. 11th Annu. SCRI Zebra Chip Rep. Session. F. Workneh, A. Rashed, C. M. Rush, eds. Fredric Printing, Aurora, CO.

23. Palermo, S., Arzone, A., and Bosco, D. 2001. Vector-pathogen-host plant relationships of chrysanthemum yellows (CY) phytoplasma and the vector leafhoppers Macrosteles quadripunctulatus and Euscelidius variegatus. Entomol. Exp. Appl. 99:347-354.

24. Purcell, A. H. 1981. Vector preference and inoculation efficiency as components of resistance to Pierce's disease in European grape cultivars. Phytopathology 71:429-435.

25. Rashed, A., Daugherty M. P., and Almeida, R. P. P. 2011. Grapevine genotype susceptibility to Xylella fastidiosa does not predict vector transmission success. Environ. Entomol. 40:1192-1199.

26. Rashed, A., Killiny, N., Kwan, J., and Almeida, R. P. P. 2011. Background matching behaviour and pathogen acquisition: plant site preference does not predict the bacterial acquisition efficiency of vectors. Arthropod Plant Interact. 5:97-106.

27. Rashed, A., Workneh, F., Gray, J., Paetzold, L., and Rush, C. M. 2012.
Relationship between time of infestation, disease development and tuber yield. Pages 22-26 in: Proc. 11th Annu. SCRI Zebra Chip Rep. Session. F. Workneh, A. Rashed, C. M. Rush, eds.

28. Saracco, P, Bosco, D., Vertti, F., and Marzachi, C. 2005. Quantification over time of chrysanthemum yellows phytoplasma (16Sr-I) in leaves and roots of the host plant Chrysanthemum carinatum (Schousboe) following inoculation with its insect vector. Physiol. Mol. Plant Pathol. 67:212-216.

29. Secor, G. A., Rivera, V. V., Abad, J. A., Lee, I. M., Clover, G. R. G., Liefting, L. W., Li, X., and De Boer, S. H. 2009. Association of 'Candidatus Liberibacter solanacearum' with zebra chip disease of potato established by graft and psyllid transmission, electron microscopy, and PCR. Plant Dis. 93:574-583.

30. Wallis, C. M., Chen, J., and Civerolo, E. L. Zebra chip-diseased potato tubers are characterized by increased levels of host phenolics, amino acids, and defense-related proteins, Physiol. Mol. Plant Pathol. In press.

31. Wen, A., Mallik, I., Alvarado, V. Y., Pasche, J. S., Wang, X., Li, W., Levy, L., Lin, H., Scholthof, H. B., Mirkov, T. E., Rush, C. M., and Gudmestad, N. C. 2009. Detection, distribution, and genetic variability of 'Candidatus Liberibacter' species associated with zebra chip complex disease 1 of potato in North America. Plant Dis. 93:1102-1115. 